\title{
S Research Square \\ Over 200,000 kilometers of river-fish habitat is lost to impoundments in Europe.
}

Piotr Parasiewicz ( $\nabla$ piotr@infish.com.pl)

S. Sakowcz Inland Fisheries Institute https://orcid.org/0000-0003-1672-3759

\section{Kamila Belka}

European Regional Centre for Ecohydrology of the Polish Academy of Sciences https://orcid.org/00000002-3002-0913

\section{Malgorzata Lapinska}

European Regional Centre for Ecohydrology

\section{Karol Ławniczak}

European Regional Centre for Ecohydrology of the Polish Academy of Sciences

\section{Pawet Prus}

S. Sakowicz Inland Fisheries Institute

\section{Mikołaj Adamczyk}

S. Sakowicz Inland Fisheries Institute

\section{Paweł Buras}

S. Sakowicz Inland Fisheries Institute

\section{Jacek Szlakowski}

S. Sakowicz Inland Fisheries Institute

\section{Zbigniew Kaczkowski}

European Regional Centre for Ecohydrology of the Polish Academy of Sciences

\section{Konga Krause}

European Regional Centre for Ecohydrology of the Polish Academy of Sciences

\section{Joanna O'Keeffe}

S. Sakowicz Inland Fisheries Institute

\section{Katarzyna Suska}

S. Sakowicz Inland Fisheries Institute

\section{Janusz Ligięza}

S. Sakowicz Inland Fisheries Institute

\section{Andreas Melcher}

University of Natural Resources and Life Sciences, Vienna Jesse O'Hanley

University of Kent https://orcid.org/0000-0003-3522-8585

\section{Kim Birnie-Gauvin}

DTU Aqua https://orcid.org/0000-0001-9242-0560 


\section{Kim Aarestrup}

Technical University of Denmark

\section{Peter Jones}

Swansea University

Joshua Jones

Swansea University https://orcid.org/0000-0001-9047-9147

\section{Carlos Garcia de Leaniz}

Swansea University https://orcid.org/0000-0003-1650-2729

\section{Jeroen Tummers}

Durham University

\section{Sofia Consuegra}

Swansea University https://orcid.org/0000-0003-4403-2509

\section{Paul Kemp}

University of Southampton https://orcid.org/0000-0003-4470-0589

\section{Hannah Schwedhelm}

Technical University of Munich

\section{Zbigniew Popek}

Warsaw University of Life Sciences

\section{Gilles Segura}

IS Environnement

\section{Sergio Vallesi}

Hydro Nexus

\section{Maciej Zalewski}

University of Łódź https://orcid.org/0000-0002-4483-6200

\section{Wiesław Wiśniewolski}

S. Sakowicz Inland Fisheries Institute

\section{Biological Sciences - Article}

Keywords: river typology, macrohabitats, ecosystem benchmarking, river habitat loss, dams, river restoration, barrier management, river fragmentation, habitat use guilds, habitat models

Posted Date: February 23rd, 2022

DOI: https://doi.org/10.21203/rs.3.rs-1287087/v1

License: (c) (i) This work is licensed under a Creative Commons Attribution 4.0 International License. Read Full License 


\section{Abstract}

We estimate over $200,000 \mathrm{~km}$ or $10 \%$ of previously free-flowing river habitat length has been lost due to impoundments, an amount equivalent to the entire length of rivers in Italy. This loss strongly depends on the biogeographical location and a type of impounding barrier. European rivers are disconnected by more than one million man-made barriers that physically limit or completely block aquatic species migration and contribute to the loss of freshwater habitats8. One of the pervasive effects of barriers is the one caused by impoundment, which directly modifies lotic (flowing) stretches of river into lentic (lake-like) habitats5. Depending on structure and composition of fish communities expected at the barrier location the biological consequences may vary. EU-wide analysis of fish communities observed at river sections with low human induced alteration resulted in a macrohabitat classification of European rivers into 15 river types with expected fish community structure. This set a baseline for assessing the impacts of six main barrier types (dams, weirs, sluices, culverts, ramps, and fords) on river fish habitats across Europe. The largest habitat losses are caused by dams, weirs and sluices in mountainous areas where fish most sensitive to ponding are expected. Although many impoundments are smaller than in lowlands their individual impacts are the greatest. Hence, regional variation in the magnitude of impoundment impact is not only a function of barrier height and density, but to large extent of biogeographical location and barrier type. Strategies for enhancing European riverine biodiversity should focus on prioritization of most sensitive regions and barrier types causing high degree of habitat fragmentation. This work is based on four novel methodological approaches: fish community grouping into habitat use guilds, continental river reference model for ecological sound river management, landscape scale application of physical habitat models and conceptual model of impoundment impacts on fish habitat.

\section{Introduction}

Hydromorphological modification is the primary reason $\left(40 \%^{1}\right)$ why European rivers and floodplains fail to achieve 'good ecological status' based on standards of the European Union (EU) Water Framework Directive $\left(\mathrm{WFD}^{2}\right)$. A chief cause of this is the presence of artificial barriers (24\% of reported hydromorphological pressures ${ }^{3}$ ), which can drastically alter upstream and downstream river morphology, ecohydrology characteristics and in-stream habitat availability ${ }^{4,5}$. Indeed, river fragmentation caused by man-made barriers is well-known to negatively impact the sustainability of freshwater ecosystems ${ }^{6-8}$ and their ability to support a wide array of ecosystem services including maintenance of natural habitats, food provision, recreation, nutrient cycling, and flow regulation ${ }^{9}$. Fragmentation of habitats by barriers is one of five main causes of biodiversity loss ${ }^{10}$. A recently published pan-European barrier inventory estimates that more than 1.5 million barriers of varying type and size are located across the European continent ${ }^{8}$, with $13 \%$ deemed legacy structures having little socio-economic value but causing potential ecological harm ${ }^{11}$. It is estimated that there are on average 0.74 barriers per river kilometer, with a median distance of $108 \mathrm{~m}($ s.e. $=44)$ between adjacent barriers ${ }^{8}$. 
The cumulative impact of these barriers on freshwater aquatic communities has not been fully documented nor are there existing measurement tools despite the dramatic loss of free-flowing large and medium sized rivers ${ }^{12}$. One of the pervasive effects of barriers is the one caused by impoundment, which directly modifies lotic (flowing) stretches of river into lentic (lake-like) habitats. Backwater impoundments created by artificial barriers alter upstream river hydraulics, creating pond-like environments that favor generalist and limnophilic species. Barriers also cause downstream changes in channel form (e.g. due to substrate starvation), flow hydrodynamics, sediment transport, water temperature, chemistry, and biology. The magnitude and extent of downstream habitat alteration is a composite of change in local river hydraulics and proximate ponding caused by downstream barriers and, therefore, difficult to quantify accurately. Ponding can be considered a source of habitat discontinuity altering the species composition up- and downstream of a barrier 5 .

Until now, little has been known about the extent of biological impact of ponding in Europe. In this study, we quantify the upstream fish habitat alteration caused by different barrier types located in a range of river types and fish communities.

\section{Geographic Diversity Of Impounding Influence}

Fish are widely considered indicator species for assessing freshwater habitat alteration ${ }^{13-15}$. There are 381 species of freshwater fish inhabiting different biogeographic regions across Europe ${ }^{16}$. Many species use similar habitats despite occurring in different geographical locations, thereby allowing us to carry out a pan-European assessment using what we called Habitat Use Guilds as indicator taxa. These are: Highly rheophilic, intolerant species; Rheophilic benthic species, preferring sandy-gravel bottom substrate; Rheophilic water column species, preferring sandy-gravel bottom substrate; Limnophilic benthic species of moderate tolerance; Limnophilic water column species of moderate tolerance; Intolerant, rheophilic benthic species, preferring detritus or pelal bottom substrate; Intolerant, water column species; Limnophilic lithophilic species of moderate tolerance; Limnophilic phytophilic species of moderate tolerance; Benthic species of moderate tolerance and Generalist / tolerant species (see Extended Data Table 1 for definitions).

The highest values of biodiversity indicators occur in environments with an intermediate instream habitat complexity in regards to light accessibility and nutrients. Habitats shape the biodiversity, biomass, and bioproductivity of rivers, creating trophic cascades that strongly regulate river ecosystems ${ }^{17,18}$. Accordingly, there is ample evidence that the habitat mosaics formed in different areas are associated with a unique community structure of aquatic fauna and flora ${ }^{19,20}$. Habitat mosaics are themselves influenced by macroscale landscape attributes. The Stream Evolution Triangle recognizes three 'highlevel' drivers of stream habitat evolution: geology, hydrology, and biology. These drivers operate through derivative drivers like catchment topography, rainfall-runoff relationships, valley slope and confinement, sediment transport regime, channel boundary characteristics, and vegetation ${ }^{21}$. In spite of human impact becoming increasingly pronounced in locally shaping habitats and ecosystems either directly or indirectly, 
to predict fish assemblage composition and structure at continental scales only catchment level attributes independent of human activity need to be taken into account. Consequently, to estimate macroscale habitat composition we selected key macroscale environmental characteristics, representing an array of environmental processes responsible for freshwater habitat creation at the catchment scale. These are: river slope, stream order, catchment size, altitude, catchment geology, and bio-climatic zone.

By combining these attributes and referencing them to pan-European fish survey data at undisturbed reference sites, we created the first fish macrohabitat classification model for Europe to estimate expected fish community structure under natural conditions (Figure 1 and 2). This involved a two-step cluster and discriminant analysis of physical and fish biological data that produced a robust and accurate model (ANOSIM R=0.98, $p<0.001$ ) of 15 Fish Community Macrohabitat Types (FCMacHT), which are uniquely characterized by different proportions of Habitat Use Guilds (see Methods for details).

\section{Anticipated Fish Responses To Impoundment}

Aquatic organisms, including fish, are typically well adapted to specific habitats occurring at certain locations and time periods. Fish habitat preferences vary in terms of available feed, substrate for spawning, flow characteristics, pelagic versus demersal or benthic lifestyles, and tolerance to physiochemical (oxygen) and habitat changes ${ }^{22}$. Using data from the available literature about habitat preferences for each Habitat Use Guild, we developed response scores reflecting each guild's sensitivity to habitat changes caused by impoundment. Results showed a gradient of response, from intolerant rheophilic species to highly tolerant generalist species (see Methods for details).

Knowing the expected guild structure at a given location, we were subsequently able to predict aggregate fish community sensitivity to impounding across Europe (Figure 3). Not surprisingly, fish in mountainous regions in the Alps, Scandinavia and southern Europe (a total of almost 450,000 km of river length) are anticipated to be the most vulnerable to ponding. These are followed by almost 1,500,000 km river length in the rest of the continent, showing lower vulnerability. The fish community is least sensitive to impoundments in over $100,000 \mathrm{~km}$ of rivers in the Mediterranean lowland. This index gives a predicted fish sensitivity to impounding but does not account yet for the density of barriers nor other for anthropogenic impacts that may be significant there.

Habitat features modified by impoundment vary considerably based on barrier type and size. An in-depth literature review ${ }^{23}$ enabled us to create a conceptual model of impoundment impacts on fish communities for different barrier types. The largest habitat reductions are expected from dams, followed by weirs, then sluices (Figure. 4). Other barrier types (culverts, fords and ramps) create much smaller and dynamic impoundments and are anticipated to have less pronounced effects.

\section{Anticipated Barrier Impacts By Type And Location}


Fish communities consist of guilds with varying sensitivity to impoundment, while different barrier types have varying impact depending on the macrohabitat area in which they are located. Given the combination of these, impounding impacts are expected to be barrier and geographically specific. To quantify this, we estimated the proportion of Residual Habitat (wRHp) according to barrier type and Fish Community Macrohabitat Type (Table 1).

The lowest wRHp values are associated with dams and weirs, followed by sluices (Table 1, Figure 4). These barriers alter river habitats the most in mountainous regions of southern Europe, the Alps, and Scandinavia, causing severe to major habitat loss. A lower degree of impact is estimated to occur in the south of the Iberian Peninsula, with substantial to moderate impact, due to the specific fish composition there. Culverts, fords, and ramps show the highest wRHp values, meaning the greatest proportion of habitat unmodified. Substantial to moderate habitat loss is still evident in mountainous rivers, especially for culverts and ramps.

\section{Projected River Habitat Loss Across Europe}

Based on our macrohabitat typology and barrier impacts framework, we make a first attempt at assessing the impact of river barriers at the European scale. Since habitat alteration by impounding with culverts, fords and ramps is a magnitude lower than with other barriers, we further focused only on barriers creating substantial impoundments. For the 92,167 identified dams, weirs, and sluices with recorded height data in the AMBER Barrier Atlas ${ }^{8}$, we estimate a total impoundment length of just over $67,000 \mathrm{~km}$, of which around $30,100 \mathrm{~km}(45 \%)$ still provides useable habitat for fish, thus translating to a net loss of approximately $36,900 \mathrm{~km}(55 \%)$ of river habitat. (Table 2). On a per barrier basis, severe habitat loss is mainly concentrated in coastal areas of western Norway and southern portions of Austria (Figure 5), though this may be down to comparatively more complete national barrier databases in these areas. Major habitat loss occurs throughout most of England, France and Northwest Europe, northern parts of Spain and Italy, and much of Eastern Europe. In contrast, rivers in the Balkans remain largely freeflowing, though currently face mounting threats from dam building and other anthropogenic pressures ${ }^{8}$. These rivers would benefit from explicit protection to protect them against future fragmentation.

We emphasize that the nearly $37,000 \mathrm{~km}$ figure for river habitat loss is, most certainly, a vast underestimate. It does not factor in small impounding barriers such as culverts, fords, and ramps. More importantly, it disregards barriers without height data (64\% for recorded dams, weirs, and sluices) and the significant underreporting of barriers (61\% overall) within the AMBER Barrier Atlas ${ }^{8}$. Correcting for missing height information and barrier underreporting, we estimate that no less than $203,100 \mathrm{~km}$ of river habitat in Europe has been lost due to barrier impounding (Table 2). This conservative approximation represents almost $10 \%$ of the entire European river network. The true amount of river habitat loss is likely much greater. Breaking it down, over $74 \%$ of habitat loss $(\sim 151,000 \mathrm{~km})$ is caused by weirs due to their high projected numbers $(n=441,829)$ relative to both dams and sluices $(n=71,010$ and $n=24,940$ respectively). By contrast, dams account for roughly $16 \%$ of habitat loss $(\sim 33,400 \mathrm{~km})$ and sluices a little over $9 \%(\sim 18,800 \mathrm{~km})$. 


\section{Discussion - Barrier Types And Location Matter}

Our pan-European classification of fish community macrohabitats (FCMacHT) provides, for the first time, a consistent natural riverine habitat taxonomy in Europe, informed by robust data analysis of fish catch data and key environmental variables available at a continental scale. It allows to differentiate barrier impacts according to the fish community structure expected at their geographical locations, documenting that not only barrier density matters in landscape level assessment of damage. It is also important for prioritization of management actions. We envisaged multiple uses of the FCMacHT typology and barrier impact assessment, from environmental and ecological studies, through river restoration planning, to water resources management and policy implementation (e.g. EU WFD). Our barrier impact assessment approach offers a complement to guidelines for river-basin management plans ${ }^{10,24,25}$, which focus more on the fish passage than habitat impact. The habitat improvement potential metrics in particular could be applied within more detailed local or regional studies and form the basis for prioritizing barrier retrofit and removal actions ${ }^{26}$ or, conversely, where building new barriers would be undesirable ${ }^{27}$.

Another key contribution of our work is the presentation of a conceptual model for assessing barriers impacts for different types of structures. Based on this analytical framework, we find that impounding from culverts, ramps, and fords results in low to moderate habitat loss, while impounding from dams, weirs, and sluices cause substantial to severe habitat loss across most of the continent, except parts of the Mediterranean with its distinctive types of fish communities (Figure 3 and Figure 4). This is not to say that smaller structures like culverts, fords, and ramps have little impact. Because of their much greater prevalence within the landscape ${ }^{8}$, they disproportionately fragment rivers and streams, and obstruct aquatic organism dispersal, potentially leading to restricted range sizes, altered population structures, reduced spawning and recruitment success, genetic isolation, and local extinction ${ }^{28,29}$. On the positive side, small barriers are relatively easy to fix through removal, replacement or installation of fish passage structures $^{8}$. We therefore suggest that effective management prioritization procedure needs to factor in not only fish community habitat structure and sensitivity to impounding (Figure 3), but also barrier density and location within river networks and the resulting influence on habitat accessibility. Contrary to common belief, a second key finding is that small impoundment dams located in mountainous areas are actually more detrimental than large impoundment dams in lowlands areas due to their more profound alteration of river hydraulics and the greater prevalence of habitat loss suffered by rheophilic species in alpine areas. On top of this, there is a higher density of small dams in mountainous areas compared to large dams in lowland areas, thus causing cumulatively greater river habitat loss.

There are over 600 thousand barriers recorded in the AMBER Barrier Atlas ${ }^{30}$, though modelling suggests there may be more than 1.5 million barriers within Europe ${ }^{8}$. Information on barrier height is available for only $38 \%$ of recorded dams, weirs, and sluices. Despite these limitations, we conservatively estimate that over $203,100 \mathrm{~km}$ of river habitat has been lost by barrier impounding. This is a good foundation to develop strategies to enhance river biodiversity by reducing river habitat loss while 
differentiating between barrier types. Increased fish passage at dams, weirs, and sluices is by itself only a partial solution. Other improvement options need to be considered, such as construction of new habitat to compensate for losses as well as full or partial removal through lowering the height of dams to reduce the size of impoundments. Improvement of riparian ecotones may provide a useful alternative that may also create refugia for downstream migrating juvenile fish. We note that protection, restoration, and enhancement of fish habitats and riparian zones not only boosts biodiversity and ecosystem productivity, but also provides wider benefits by improving water quality and other ecosystem services, like recreation, fishing, and resilience to climate change ${ }^{31}$, and supports wider plans such as landscape and forest restoration.

Our study forms a fundamental basis for further assessment of river barrier impacts. Certainly, more comprehensive barrier data is needed to derive further estimates of habitat loss for different fish communities and barrier types. Yet at present, most national inventories are far from complete, especially for the large number of smaller barriers, such as culverts, fords, and ramps. Furthermore, key structural information, like barrier height, is often missing and few databases account for natural barriers. This can have significant consequences for management decisions, leading to costly expenditure for low to moderate ecological benefit. Clearly, more complete and more detailed barrier data as well as novel barrier prioritization tools capable of accounting for data uncertainty would go a long way toward enhancing barrier impact assessment and river restoration planning. Nevertheless, even at current data quality some interesting estimates can be performed. For example, if we hypothesize that on average impounding rivers by dams, weirs and sluices will increase the river width by only $5 \mathrm{~m}$, at the total length of impounded rivers of $380,154 \mathrm{~km}$, the increase of wetted surface area will be close to 200,000 ha (of mostly shallow water). This may have a serious impact in light of climate change due to increased water warming, evaporation and methane release into the atmosphere, which are known effects of impounding rivers.

The most striking result though is the length of calculated habitat loss. Although $10 \%$ of the total may not appear to be particularly much, to recognize the magnitude of damage we need to consider that this is equivalent to the length of all the rivers in such large country like Italy is about $200,000 \mathrm{~km}$. Since, as mentioned before, this is only one aspect of damages to biodiversity of the barriers, the sum total of all habitat loss up- and downstream will be much larger. This allows to safely conclude that man-made barriers have profound impact on fish habitat in European rivers, and further justifies one of the main goals of EU 2030 Biodiversity Strategy to create at least $25,000 \mathrm{~km}$ of free flowing rivers ${ }^{32}$. By pointing out that the impact of impoundments is very much depending on their zoo-geographic location, this study fills one of the knowledge gaps for prioritization of barrier removals called for in the Guidance on Barrier Removal for River Restoration ${ }^{33}$.

\section{Methods}

\section{Overview}


This paper presents a riverine macrohabitat typology to support barrier impact assessment and evaluates management and restoration efforts in compliance with the EU WFD. It builds on the notion of a template riverine habitat composition to support an expected fish community structure. The typology can further be used to predict the level of "deviation" of freshwater communities from their predicted baseline. The habitat templates are predicted from broad physio-geographic and environmental features and validated with fish catch data.

The following steps were performed to develop the macrohabitat typology:

Identify fish Habitat Use Guilds from fish biological data collected at undisturbed sites with unmodified or least modified habitat conditions. These guilds serve as proxies habitat preferences.

Define fish community riverine macrohabitat types (FCMacHT) based on environmental variables and fish data.

Define expected fish community structure for each FCMacHT.

Apply macrohabitat typology to the entire European river network to predict FCMacHT based on broad environmental characteristics.

Further analysis based on FCMacHT includes:

1. Estimating the proportion of habitat loss due to impounding for each barrier type based on its geographic location.

2. Generating maps of potential habitat loss due to impoundments in European rivers.

3. Assessing spatial extend of impoundment impacts based on available barrier inventories and projected underreporting of barriers.

Key assumptions and limitations regarding the assessment of the barrier impacts include the following:

1. Fish assemblages are considered good indicators of the environmental state of rivers ${ }^{34}$. Due to their high mobility and relatively long lifespan, fish use various habitats within river ecosystems, so they are particularly sensitive to disturbances in river morphology ${ }^{35}$. As the only riverine organisms that actively migrate long distances, fish are strongly affected by disturbance to the river continuum ${ }^{36}$.

2. While species composition varies between biogeographic regions, it is effective to assess fish assemblage responses to riverine habitat changes caused by barrier impacts on a continental scale using Habitat Use Guilds.

3. Development of a conceptual model of barrier impacts on fish habitats only considers upstream changes to river hydromorphology in relation to European macrohabitat river types.

4. Barriers assessed are assumed to be constructed to account for good ecological potential of the water body (e.g., ramps are constructed out of rocks, culverts are not perched, dams have fish passage facilities, and mitigation measures have been implemented). 


\section{Fish data}

The source of fishery data is the European Intercalibration database gathered between 2006 and 2011 under the auspices of the European Commission Joint Research Centre (JRC) to support implementation of the Water Framework Directive ${ }^{37}$. This database contains information on 4561 fish survey sites in 22 countries. The database consists of several tables describing basic physical parameters for each site, details of each fishing campaign, and catches obtained by electrofishing surveys. Data on anthropogenic pressures, including impounding, are available, thereby enabling distinction between reference and disturbed sites. The Intercalibration database was used with the permission of JRC and data owners from 19 EU member states involved. A similar dataset for Poland, gathered during the autointercalibration process ${ }^{38}$, was used with the permission of the Chief Inspectorate for Environmental Protection, Poland.

The final database containing 5497 survey sites was subsequently filtered based on pressure criterion to select anthropogenically undisturbed sites. Pressures were grouped into five categories: i) connectivity, ii) hydrological alteration, iii) morphological alteration, iv) water quality, and v) navigation, recreation and biological pressure from invasive species. Sites least impacted were considered references for the purpose of river ecosystem quality assessment. Of the 1315 sites (river reaches) meeting criteria for being least impacted, a subset of 1099 in 17 countries was identified considering data use limitations and data quality issues (i.e., precision of the site location referenced to the river network database, discussed below). The location of fishing sites is presented in Extended Data Figure 1. To identify regional fish assemblages, we analyzed Intercalibration fish records from river sites classified as undisturbed.

\section{Fish Habitat Use Guilds}

Fish surveys across a large region are affected by variability due to different surveyors, sampling methodology, seasonality, and year of survey. This affects the accuracy of fish community prediction models. To account for this, predicted fish distributions can be fit into generic distribution patterns such as those used in biocomplexity models ${ }^{39}$. The Target Fish Community approach ${ }^{40}$ uses a model of ranking relative abundance of species observed during a survey, which can, in turn, be used to calculate expected proportions according to a biocomplexity formula. Fish catch data were subject to this procedure to level out the influence of natural variability on fish catch data.

To further reduce regional variability between samples, it has been proposed to group species into Habitat Use Guilds and estimate the structure of a guild assemblage rather than species. This approach was first used in Poland to determine environmental flow rules for the country 41,42 .

Habitat Use Guilds were determined by modifying the fish guild classification created for the EFI+ Project ${ }^{43}$ and informed by other literature sources ${ }^{22,44,45}$. We began with the EFI+ Manual ${ }^{15}$, where each of the 302 species occurring in European rivers was ascribed to a guild: intolerant or tolerant species, 
benthic or rheophilic species, lithophilic or phytophilic species, and insectivorous or omnivorous species. Eleven Habitat Use Guilds were created by combining particular guild characteristics (i.e., tolerance to change, flow preference, and spawning and feeding behaviour) to represent dominant habitat needs and a range of tolerance to environmental gradients (Extended Data Table 1). To capture temporally predominant habitat use, emphasis was given to foraging behavior as prevalent during the time of capture. Thus, while naming the guilds, we generalized the classification used for spawning preference description (e.g., phytophilic spawners) and applied it to adult life stages. Hence, phytophilic species are here means considered as preferring vegetation cover during the rearing and growth life stage and lithophilic species as fish most commonly found over stony substrate. Fish species belonging to a particular Habitat Use Guild are shown in Extended Data Table 2 and a detailed description of the Habitat Use Guilds together with their habitat preferences is provided in the Supplementary Information.

\section{Broad-scale environmental influences on fish habitats}

In this study, we selected coarse-scale, hence unaffected by human disturbance, environmental characteristics of rivers and their catchments to use it as proxies for habitat formation. They include altitude and slope of river segment, stream order, catchment size, geology, and bioclimatic conditions. These features determine such habitat characteristics as flow velocity, riverbed width and depth, and longitudinal profile. In turn, catchment geology (i.e., the physical and chemical properties of rocks and soils) contributes to riverbed substrate material formation, relief of the catchment and drainage network density, shape of the river valley and riverbed cross-section, as well as the main physico-chemical character of surface waters. Finally, climatic variables, such as temperature, precipitation and insolation intensities together with temporal patterns determine flow regime, physico-chemical properties of waters, vegetation, and phenological seasons. Intentionally, landcover and water pollutants have not been selected as attribute as they are the most sensitive to human induced alteration.

The river network and its geometric characteristics was obtained from the River and Catchment Database derived from the Catchment Characterization Model (CCM, v2.1) ${ }^{46}$, which contains spatially attributed information on slope, altitude, Strahler stream order, and catchment area (Extended Data Figure 2).

Catchment geology was derived from the International Hydrogeological Map of Europe (IHME1500, v1.2) at a scale of 1:500,000 47,48 and its structured lithological attributes of bedrock formations. Rock formations have been classified into calcareous and siliceous types based on Water Framework Directive recommendations for stream classification. Location of organic material was derived from the European Soil Database (ESDB, v2.0) based on soil type and the soil parent material attributes of soil mapping units. Details regarding classification of geological formations are shown in Extended Data Table 6. Geological type has been attributed to river reaches based on location of its geometric center. Where data for river reaches were missing, values were derived from the nearest river segments upstream that had recorded information. 
Finally, climate related factors were obtained from the Environmental Stratification of Europe ${ }^{49}$, where environmental zones have been delimited by modeling a set of environmental and climatic variables forming regions of homogeneous environmental conditions.

Geographic data available for the entire study area were used to assure best available data consistency among regions. Using pan-European datasets, however, often involves compromising on accuracy and precision. Even though we used the best available datasets, we are aware of several issues, which could affect our results but, which could not be resolved at the time of the analysis. In particular, river course precision and accuracy issues manifest themselves especially in the low-relief terrain by incorrect alignment in vertical and longitudinal dimensions. This could, in some cases, lead to the point that a river misses its correct outflow, and in the worst cases splits into two rivers flowing in two distinct directions, entailing wrong catchment attribution ${ }^{50}$. Low precision and accuracy of geology and soil data might have produced further inconsistencies with river network data. Some examples are depicted in Extended Data Figure 3. Calculation of percent error revealed high relative error for selected locations (Extended Data Table 4), which could not be corrected despite various quality checks (details in Supplement). Spatial data preparation, handling, and analysis were all performed in ArcMap 10.5.

\section{Statistical analysis and extrapolation of results}

A two-step cluster and discriminant analysis was applied to establish the relationship between catchment environmental settings and expected fish macrohabitats (using observed fish community structure as a proxy). In the first step, non-hierarchical cluster analysis was conducted using the Intercalibration data from 1099 river sites classified as Non-Disturbed Sites in the database. Cluster analysis was applied to two datasets sequentially. The first dataset consisted of physical attributes of the sampling sites obtained from the broad-scale environmental attributes described previously. This was clustered into samples with similar habitat characteristics (Extended Data Figure 4). Cluster groupings were then added as an additional variable to the biological data on Habitat Use Guilds proportions at each site (obtained from the Intercalibration dataset of undisturbed sites) to produce a mixed data set of guilds/physical clusters (Extended Data Figure 5). This second dataset was then clustered, resulting in one of 15 fish community macrohabitat type $(\mathrm{FCMacHT})$ classes assigned to each sampling site. The Habitat Use Guilds proportions expected to occur within a river reach of a specific habitat composition were determined using a Target Fish Community method for each FCMacHT. For each river type, 10 NonDisturbed Sites $(n)$ were selected at random, from which the sum of guild proportions was calculated and ranked, and the reciprocal rank calculated. The number of the sample sites is based on the metaanalysis of publicly available Target Fish Community reports from rivers $(n=22)$ in New Hampshire (https://www.des.nh.gov/resource-center/publications?keys=tfcrpt). In these studies $\mathrm{n}$ was defined using Multivariate Pseudo Standard Error (MultSE ${ }^{51}$ ) and only rarely exceeded $n=10$. Expected guild proportions were then obtained by dividing each guild reciprocal rank by the sum of the reciprocal ranks and plotted as pie charts for each FCMacHT (Figure 2). 
A distance matrix was created by standardizing the data using Gower and Manhattan similarity distances for the physical and mixed datasets, respectively ${ }^{52,53}$. The number of clusters was determined with the help of scree and silhouette plots. A partitioning around medoids (PAM) clustering model was applied ${ }^{54}$. Cluster plots and silhouette plots, as well as box plots, were created for each variable. Subsequently, data discrimination with analysis of similarities (ANOSIM) was performed to verify model performance (Extended Data Figure 4, Extended Data Figure 5).

Finally, the relationship between macrohabitat type and broad-scale environmental attributes was analyzed to define a riverine macrohabitat typology for the entire European river network. To this end, the FCMacHT class was added to the physical attributes of each undisturbed site as a grouping variable to perform classification and regression tree (CART) analysis ${ }^{55}$ for determining how FCMacHT is distributed along the gradients for physical descriptors (Extended Data Figure 6). A complexity parameter plot was used to determine an acceptable relative error for pruning the decision tree. Following this, the decision tree was applied to all water bodies of Europe with specified environmental attributes to determine their FCMaCHT class (Supplement, Box 2).

A summary of basic statistics of the Non-Disturbed Site dataset in comparison with the extrapolated dataset is shown in Extended Data Table 5. Statistics for each FCMacHT class are presented in Extended Data Table 6.

\section{River barrier types}

Barriers have been constructed to serve multiple economic and societal goals. Their impacts on river habitats depend to a greater or lesser extent on the magnitude and permanency of the impoundments they form. In our analysis, we consider six barrier types - dams, weirs, sluices, culverts, fords, and ramps - varying in function, size, and impoundment extent ${ }^{30}$. Three of them are usually constructed specifically to create impoundments (dams, weirs, and sluices). Dams are hydrotechnical structures designed to store water and create permanent impoundments ${ }^{11}$. They are the largest and least frequent barrier type in Europe $^{8}$. Weirs are typically smaller and constructed to regulate flow conditions and upstream water levels. Sluices form a movable barrier (horizontal or vertical) aimed at controlling water levels and flow rates in rivers and streams. Culverts are designed to convey streams and small rivers through or under an obstruction, such as a road or dike. Fords create wadeable shallows for crossing a stream, while ramps (or bed sills) help stabilize the channel bed and reduce erosion ${ }^{11}$. The last three are the most common barriers in European rivers, yet their ponding effects are spatially and temporally restricted ${ }^{8}$. Using the Amber Barrier Atlas, we were able to determine known barrier locations and their height to estimate the extent of backwater effect of dams, weirs, and sluices using pan-European river network and gradient data ${ }^{46}$. 
To determine the impact of barrier impoundments on habitat availability for Habitat Use Guilds, we developed a conceptual model using available scientific information. This was preceded by an extensive review of the literature with findings discussed in a technical workshop for fish biology experts involved in the AMBER project ${ }^{23}$. We identified 21 key riverine habitat attributes, which are important for aquatic organisms in rivers and likely to be modified by impounding. (Extended Data Table 7). These are:

- flow velocity (high and low velocity)

- depth (deep and shallow areas)

- substrate (interstitial spaces, sandy or muddy bottom, and gravel)

- instream cover (woody debris or boulders)

- physico-chemical conditions (oxygenation, water temperature, and nutrient content)

- vegetation (rheophilic vegetation or mosses, macrophytes, canopy shading from banks, and overhanging vegetation)

- structure of banks (undercut banks)

- floodplain accessibility

- habitat continuity

- flow stability

For each Habitat Use Guild, these attributes were assessed for their importance to fish presence and abundance according to information found in the literature. Subsequently, for each habitat attribute, scores were assigned to obtain a habitat suitability index (HSI):

$0=$ not important

$0.5=$ moderately important

1 = very important

The summed HSI value in the bottom row of Extended Data Table 7 reflects the suitability of all listed habitat attributes for a given fish guild. This value is highest for specialised river guilds and lowest for generalists. To evaluate regional sensitivity of fish communities to habitat change, we weighted guild specific suitability with the proportion of each guild for a given FCMacHT and divided by the maximum suitability value of 21 , which assumes all attributes are very important. These relative sensitivity levels were then split into 3 classes: lowest, moderate, highest with values less than $45 \%$, between $45 \%$ and $55 \%$, and greater than $55 \%$, respectively (Figure 3 ).

HSIreflects the importance of habitat attributes to fish presence, but not how attributes change in response to the presence of the impoundment.

Relative change of a habitat attribute prevalence was assessed from major reduction to major increase, using five categories ranging in value from 0 to 2, to obtain a barrier impact $(B I)$ index (Extended Data 
Table 8):

$0.0=$ major reduction

$0.5=$ small reduction

$1.0=$ no change

$1.5=$ small increase

2.0 = major increase

Impoundment can have a negative impact on some fish groups through reduction of area with suitable attributes (e.g. less area with high velocities), hence the loss of lotic habitats, while other guilds (i.e., generalists and limnophilic phytophilic species) can benefit from changes caused by the presence of a barrier. Accordingly, the Habitat Use Guild's response to a barrier can be either negative or positive because of habitat becoming more or less suitable.

Combining the two indices (HIS and $\mathrm{BI}$ ) produces a Habitat Suitability Alteration index (HSA) for Habitat Use Guilds affected by pressures from different barrier types. For example, for rheophilic species high water velocity was determined to be a critically important habitat attribute ( $H S /=1)$. Since presence of dams cause impoundment of water and decrease flow velocity, this results in a major reduction of habitat area with this particular habitat feature $(B I=0)$ and in turn, high suitability loss $(H S A=1 \times 0=0)$. Similarly, macrophytes are moderately important for limnophilic benthic species of moderate tolerance $(H S I=0,5)$. While dams increase macrophytes abundance to a large extent $(B I=2)$, thus the $H S A$ for this attribute is 1 , indicating that the habitat suitability dependent on this attribute will stay unchanged under impoundment. The HSA value above 1 would indicate an increase of suitable habitat area due to an attribute change. In case a habitat feature is not important for a specific guild the HSA values would equal zero, thus not affecting the overall suitable habitat area. The sum of scores for Habitat Use Guild indicates a composite habitat suitability alteration due to the construction of a particular barrier type. To derive a measure of residual habitat proportion for each Habitat Use Guild, values were normalized by the total Habitat Suitability Index. After normalizing, values were further weighted by Habitat Use Guilds proportions and summed for all guilds to determine an overall weighted remaining habitat proportion () for a given $\mathrm{FCMacHT}$ using the following the formula:

$$
w R H p=\sum_{1}^{m}\left(G P(i) \times \frac{\sum_{1}^{n} \ldots(H S I(i, j) \times B I(j))}{\sum_{1}^{n} \equiv H S I(i, j)}\right) \times 100 \%
$$

where: 


$$
\begin{aligned}
& w R H p \quad=\text { weighted remaining habitat proportion (\%) } \\
& m \quad=\text { number of guilds, indexed by } i \\
& n=\text { number of habitat attributes, indexed by } j \\
& H S I(i, j)=\text { Habitat Suitability Index of habitat attribute } j \text { for guild } i \\
& B I(j)=\text { barrier impact index for habitat attribute } j \\
& G P(i)=\text { Habitat Use Guild proportion of guild } i \text {. }
\end{aligned}
$$

This formula was used to estimate the impact of each barrier type on habitat suitability and availability for the expected fish community of each FCMacHT river type, expressed as the percentage of the remaining suitable habitat for fish communities. Note that:

$H S A=H S I \times B I$

Values for range from 0 to $200 \%$, with $0 \%$ indicating no suitable habitat due to full loss of all habitat attributes important to each fish guild, $100 \%$ indicating no barrier impact, and $200 \%$ corresponding to a theoretical major increase of suitable area (for generalist species for example).

\section{Barriers impact on European rivers}

The AMBER Barrier Atlas ${ }^{30}$ was used to identify existing barriers in Europe. The Atlas contains all barriers contained in public inventories, be it state-owned, international or regional. The barriers with known barrier type were attributed with the FCMacHT of the catchment they belong to, with assigned based on Table 1. Values of for each barrier were plotted spatially on the map and the median value used to color code catchments (Figure 5).

Aggregate impounding length was determined for dams, weirs, and sluices with barrier height information. Barrier height was taken as the difference between bottom of the river bed and the lowest point on the crest of the barrier. The impoundment length was, in turn, estimated by dividing barrier height by slope. Total impoundment length for each barrier type was then corrected for barrier specific reporting errors published $\mathrm{in}^{8}$, as well as missing barrier height data within the AMBER Barrier Atlas. Total river habitat loss in Europe ( ), measured in km, was calculated with the formula: 


$$
\text { Hloss }=-\sum_{1}^{T}\left(\frac{\sum_{1}^{N(t)}: \ldots:\left(\frac{h}{s} \times w R H p(t)\right)}{(1-\operatorname{Err}(t)) \times p(t)}\right)
$$

where:

$$
\begin{array}{ll}
h & =\text { barrier height }(\mathrm{m}) \\
s & =\text { river slope (\%) } \\
T & =\text { number of barrier types (n), indexed by } t \\
N(t) & =\text { number of barriers (n) of type } t \\
w R H p(t) & =\text { remaining habitat proportion (\%) for barrier type } t \\
p(t) & =\text { proportion of barriers (\%) of type } t \text { with height information } \\
\operatorname{Err}(t) & =\text { reporting error for barrier type } t \text { based on modelled barrier densitys. }
\end{array}
$$

The simplified formula used for estimating the impoundment length $(h / s)$ of individual barriers was compared with two similar formulas used in the field of hydraulic engineering (Extended Data Table 9) and is discussed in the Supplement.

\section{Declarations}

\section{Acknowledgements}

This work builds upon research carried out for the EU funded projects Adaptive Management of Barriers in European Rivers (AMBER) and Fishfriendly Innovative Technologies for Hydropower (FIThydro). Representatives of resource agencies of Austria, Belgium, Bulgaria, Croatia, Czech Republic, England and Wales, Estonia, Finland, Greece, Hungary, Ireland, Lithuania, Luxemburg, Netherlands, Norway, Scotland, Slovakia, Slovenia, Spain, Sweden and Poland gave their permission to use the fish biological data in JRC database. We would like to thank all members of AMBER consortium for their support and encouragement and particularly: Victoria Hurst, Luca Borger of Swansea University, UK; Lucio Marcello of University of Highlands and Islands, UK; Sara Fernandez Fernandez of University of Oviedo, Spain; Peter Gough of World Fish Migration Foundation, Netherlands; Guillermo Giannico of Oregon State University , USA; Joshua Royte of TNC, USA; ClausTill Schneider of RWE Generation SE, Germany, Laura Wildman of Biohabitats, USA.

\section{Author contributions}

P.P. designed and led the study. P.P., K.B., M. Ł. led the work and organized the data collection,

P.P., K.B., wrote the initial draft of the manuscript with essential input from J. O'H., C. G. d. L, H. S., M. Ł., M. Z., J. T., K. B-G, K.A., S.C., P.K., A. M., K.S., P.Pr, G.S. 
P. Pr., M.A., biological data collection, quality control and calculated fish community composition for FCMacHT. P. Pr., M.A., J. Sz., P. B., A.M., W. W., J. L., Z. K., developed habitat use guilds classification, P.P. K. Ł. Statistical analysis, P.P., M. Ł. P. Pr, Z.K., M. Z., J.J., K.K. developed design of conceptual barrier impact model. Z.P. created concept of impoundment length calculation. K. B., J. O'K. GIS analysis and maps design. All co-authors critically revised and approved the edited manuscript.

\section{Competing interest declaration}

The authors declare no competing interests.

\section{Additional information:}

Correspondence and requests for additional materials should be addressed to PP.

\section{Supplementary Information is available for this paper}

Use the links below to download the following data:

- GIS dataset of FCMacHT classes assigned to the European river network, together with values for all environmental attributes (spatial dataset).

GIS dataset of undisturbed sites (UDS) with assigned environmental attributes and fish guild proportions for each site.

\section{References}

1. European Environment Agency. Chapter 4 Freshwater. in The European environment - state and outlook 2020 Knowledge for transition to a sustainable Europe 92-111 (2020).

2. European Commission. Directive 2000/60/EC of the European Parliament and the Council establishing a framework for Community action on water policy. Official Journal of the European Communities OJ L 327, 22.12.2000, p. 1. (2000).

3. European Commission. Fitness Check of the Water Framework Directive, Groundwater Directive, Environmental Quality Standards Directive and Floods Directive Directive 2000/60/EC of the European Parliament and of the Council establishing a framework for the Community action in the field of water policy Directive 2006/118/EC of the European Parliament and of the Council on the protection of groundwater against pollution and deterioration Directive 2008/105/EC of the European Parliament and of the Council on environmen.... 439, 177 (2019).

4. Birnie-Gauvin, K., Aarestrup, K., Riis, T. M. O., Jepsen, N. \& Koed, A. Shining a light on the loss of rheophilic fish habitat in lowland rivers as a forgotten consequence of barriers, and its implications for management. Aquatic Conservation: Marine and Freshwater Ecosystems 27, 1345-1349 (2017). 
5. Jones, P., Consuegra, S., Börger, L., Jones, J. \& Garcia de Leaniz, C. Impacts of artificial barriers on the connectivity and dispersal of vascular macrophytes in rivers: A critical review. Freshwater Biology 65 , 1165-1180 (2020).

6. Birnie-Gauvin, K., Tummers, J. S., Lucas, M. C. \& Aarestrup, K. Adaptive management in the context of barriers in European freshwater ecosystems. Journal of Environmental Management 204, 436-441 (2017).

7. Jones, J. et al. A comprehensive assessment of stream fragmentation in Great Britain. Science of The Total Environment 673, 756-762 (2019).

8. Belletti, B. et al. More than one million barriers fragment Europe's rivers. Nature 588, 436-441 (2020).

9. Podschun, S. A. et al. RESI - Anwendungshandbuch. Ökosystemleistungen von Flüssen und Auen erfassen und bewerten. IGB vol. 31/2018 www.resi-project.info/handbuch (2018).

10. Baudoin, J. M. et al. The ICE protocol for ecological continuity. Assessing the Passage of Obstacles by Fish. Concepts, Design and Application. (2014).

11. Amber Consortium. Tools for managing and restoring connectivity in European rivers. AMBER Policy Brief No 2. (2020).

12. Grill, G. et al. Mapping the world's free-flowing rivers. Nature 2019 569:7755 569, 215-221 (2019).

13. Pont, D. et al. Assessing river biotic condition at a continental scale: A European approach using functional metrics and fish assemblages. Journal of Applied Ecology 43, 70-80 (2006).

14. Schmutz, S. et al. Spatially based methods to assess the ecological status of riverine fish assemblages in European ecoregions. Fisheries Management and Ecology 14, 441-452 (2007).

15. EFI+ Consortium. Manual for the application of the new European Fish Index-EFIt. A Fish-Based Method to Assess the Ecological Status of European Running Waters in Support of the Water Framework Directive. (2009).

16. Freyhof, J. \& Brooks, E. European Red List of Freshwater Fishes. (Publications Office of the European Union, 2011). doi:10.2779/85903.

17. Zalewski, M., Bis, B., Frankiewicz, P. \& Puchalski, W. The importance of the riparian ecotone and river hydraulics for sustainable basin-scale restoration scenarios. Aquaric Conserv: Mar. Freshw. Ecosyst. 8, 287-307 (1998).

18. Zalewski, M., Thorpe, J. E. \& Naiman, R. J. Fish and riparian ecotones - A hypothesis. Ecohydrology and Hydrobiology 1, 11-24 (2001). 
19. Poff, N. L. R. \& Ward, J. v. Physical habitat template of lotic systems: Recovery in the context of historical pattern of spatiotemporal heterogeneity. Environmental Management 14, 629-645 (1990).

20. Parasiewicz, P. Using Mesohabsim to develop reference habitat template and ecological management scenarios. River Research and Applications 23, 924-932 (2007).

21. Castro, J. M. \& Thorne, C. R. The stream evolution triangle: Integrating geology, hydrology, and biology. River Research and Applications 35, 315-326 (2019).

22. Freyhof, J. \& Kottelat, M. Handbook of European freshwater fishes. (Publications Kottelat, Cornol and Freyhof, 2007).

23. AMBER Consortium. MS1: Literature database of impacts of river fragmentation on aquatic taxa. (2017).

24. SNIFFER. WFD111 Phase 2a Coarse Resolution Rapid-Assessment Methodology to Assess Obstacles to Fish Migration. Field Manual Level A Assessment. (2010).

25. Kerr, J., Vowles, A., O'Hanley, J. \& Kemp, P. D.1.1 Guidance on Stream Barrier Surveying and Reporting. Part A: Locating, Surveying and Prioritising Mitigation Actions for Stream Barriers. AMBER Consortium. (2016).

26. Kemp, P. S. \& O'Hanley, J. R. Procedures for evaluating and prioritising the removal of fish passage barriers: A synthesis. Fisheries Management and Ecology 17, 297-322 (2010).

27. Ioannidou, C. \& O'Hanley, J. R. Eco-friendly location of small hydropower. European Journal of Operational Research 264, 907-918 (2018).

28. Tummers, J. S., Hudson, S. \& Lucas, M. C. Evaluating the effectiveness of restoring longitudinal connectivity for stream fish communities: towards a more holistic approach. Science of the total environment 569-570, 850-860 (2016).

29. Frankiewicz, P., Radecki-Pawlik, A., Wałęga, A., Łapińska, M. \& Wojtal-Frankiewicz, A. Small hydraulic structures, big environmental problems: is it possible to mitigate the negative impacts of culverts on stream biota? Environmental Reviews 29, 510-528 (2021).

30. AMBER Consortium. The AMBER Barrier Atlas. A Pan-European database of artificial instream barriers. Version 1.0 June 29th 2020. (2020).

31. Kiedrzyńska, E., Wagner, I. \& Zalewski, M. Quantification of phosphorus retention efficiency by floodplain vegetation and a management strategy for a eutrophic reservoir restoration. Ecological Engineering 33, 15-25 (2008). 
32. European Commission. Communication From The Commission to The European Parliament, The Council, The European Economic and Social Committee and The Committee Of The Regions EU Biodiversity Strategy for 2030 Bringing nature back into our lives. 27 (2020).

33. European Commission. Biodiversity Strategy 2030 Barrier Removal for River Restoration. (2021).

34. Roset, N., Grenouillet, G., Goffaux, D., Pont, D. \& Kestemont, P. A review of existing fish assemblage indicators and methodologies. Fisheries Management and Ecology 14, 393-405 (2007).

35. Schinegger, R., Trautwein, C., Melcher, A. \& Schmutz, S. Multiple human pressures and their spatial patterns in European running waters. Water and Environment Journal 26, 261-273 (2012).

36. McCabe, D. J. Rivers and Streams: Life in Flowing Water. Nature Education Knowledge 1, 1-14 (2010).

37. JRC. WFD Intercalibration Report. Phase 2: Milestone report. (2011).

38. Prus, R. P., Wiśniewolski, W. \& Adamczyk, M. Przewodnik Metodyczny do Monitoringu Ichtiofauny w Rzekach. (Główny Inspektorat Ochrony Środowiska, 2016).

39. Bak, P. How nature works. (Copernicus, 1996).

40. Bain, M. B. \& Meixler, M. S. A target fish community to guide river restoration. River Research and Applications 24, 453-458 (2008).

41. Pegg, M. A., Behmer, A. T., Parasaweicz, P. \& Rogers, J. N. Application of mesohabitat fish use information to identify guilds for lotic systems. Journal of Applied Ichthyology 30, 1065-1068 (2014).

42. Parasiewicz, P., Prus, P., Suska, K. \& Marcinkowski, P. “E = mc2" of Environmental Flows: A Conceptual Framework for Establishing a Fish-Biological Foundation for a Regionally Applicable Environmental Low-Flow Formula. Water 10, 1501 (2018).

43. Melcher, A., Schmutz, S., Haidvogl, G. \& Moder, K. Spatially based methods to assess the ecological status of European fish assemblage types. Fisheries Management and Ecology 14, 453-463 (2007).

44. Brylińska, M. Ryby Stodkowodne Polski [Freshwater Fishes of Poland]. (Wydawnictwo Naukowe PWN, 2000).

45. Froese, R. \& Pauly, D. FishBase. https://www.fishbase.org (2021).

46. Vogt, J. et al. A pan-European river and catchment database. JRC Reference Reports (2007). doi:10.2788/35907. 
47. BgR \& UNESCO. International Hydrogeological Map of Europe 1: 1,500,000 (IHME1500). Digital map data v1.1. (2014).

48. Duscher, K. \& Günther, A. Spatial Data of the International Hydrogeological Map of Europe 1:1 $, 500,000$ in Vector Format (Version IHME1500 v 1.1 ). (2014).

49. Metzger, M. J. The Environmental Stratification of Europe [dataset]. (2018) doi:https://doi.org/10.7488/ds/2356.

50. de Jager, A. L. \& Vogt, J. v. Development and demonstration of a structured hydrological feature coding system for Europe. Hydrological Sciences Journal 55, 661-675 (2010).

51. Anderson, M. J. \& Santana-Garcon, J. Measures of precision for dissimilarity-based multivariate analysis of ecological communities. Ecology letters 18, 66-73 (2015).

52. Gower, J. C. A General Coefficient of Similarity and Some of Its Properties. Biometrics 27, 857 (1971).

53. Krause, E. F. Taxicab Geometry: an adventure in non-Euclidean geometry. (Dover Publications, 1987).

54. Park, H. S. \& Jun, C. H. A simple and fast algorithm for K-medoids clustering. Expert Systems with Applications 36, 3336-3341 (2009).

55. De'ath, G. \& Fabricius, K. E. Classification and regression trees: a powerful yet simple technique for ecological data analysis. Ecology 81, 3178-3192 (2000).

56. EEA. European catchments and Rivers network system (Ecrins) dataset. (2012).

57. Parasiewicz, P. et al. Environmental Flows Determination and Monitoring with Hydraulic Habitat Models-Pushing the Boundaries of Habitat Models Application. Water 2019, Vol. 11, Page 1950 11, 1950 (2019).

\section{Tables}

Tables 1 and 2 are available in the supplementary files section.

\section{Figures}




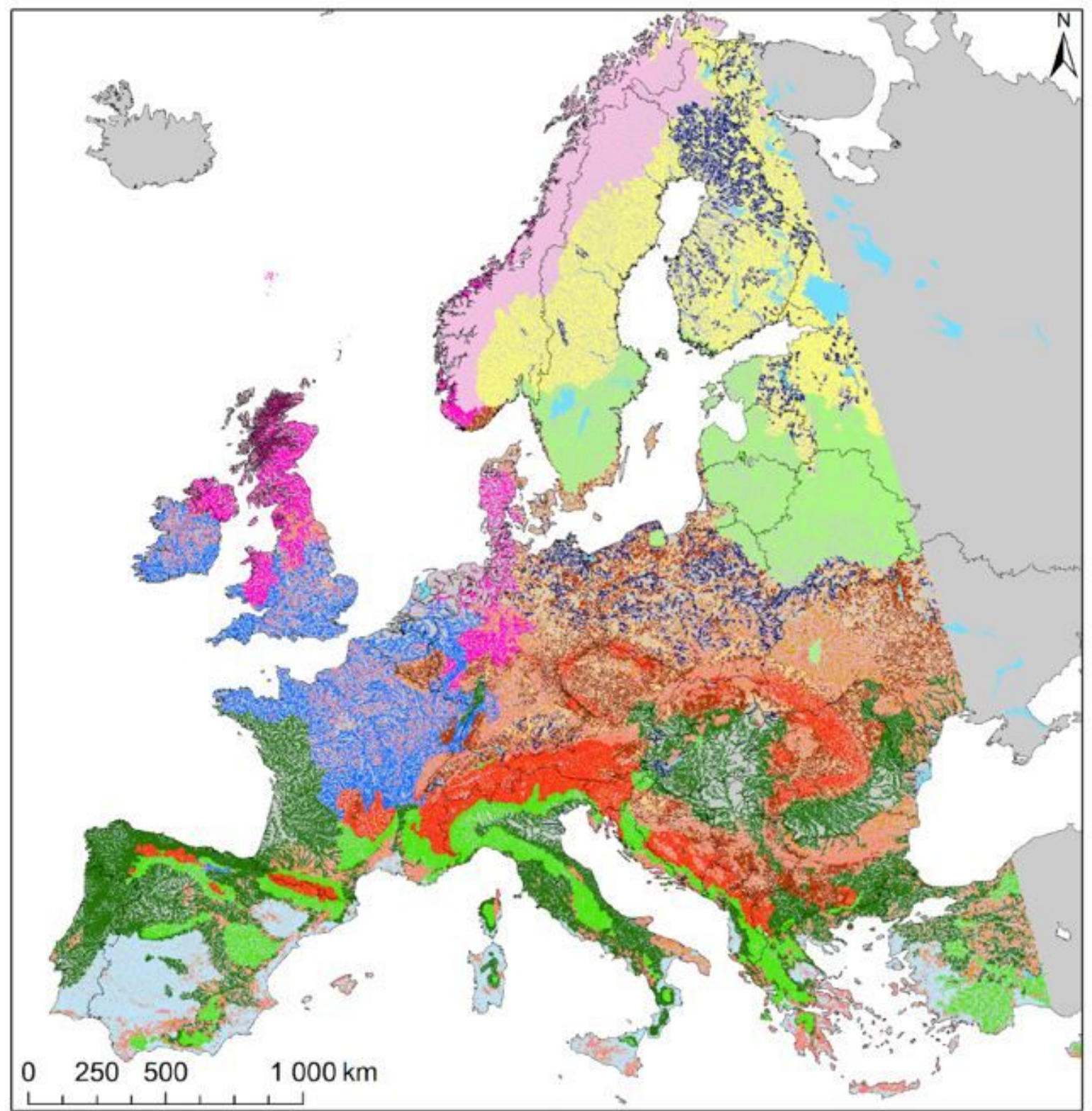

\section{Fish Community Macrohabitat Types (FCMacHT)}

-1. Pan-European calcaerous headwaters

-2. Mountain, Alpine

-3. Central European sub-mountain and highland

-4. Calcareous Alpine and highland

-5 . Continental upland and lowland headwaters

6. Boreal lowland

-7. Nemoral lowland

-8. Mediterranean mountain and upland
-9. South European plains and highland

10. Mediterranean lowland

-12. Lowland organic

-13. Boreal mountain and highland

-14. North Atlantic lowland and upland

-15. North Atlantic peatland

\section{Figure 1}

FCMacHTs in European running waters. Data source: CCM v2. $1^{46}$ for river segments, ERCINS ${ }^{56}$ for country borders. 


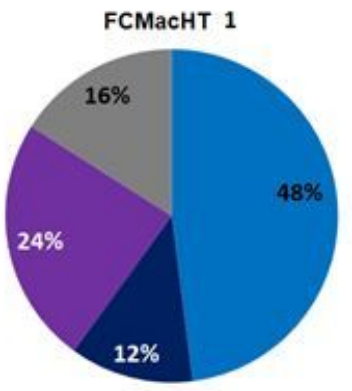

FCMacHT 6

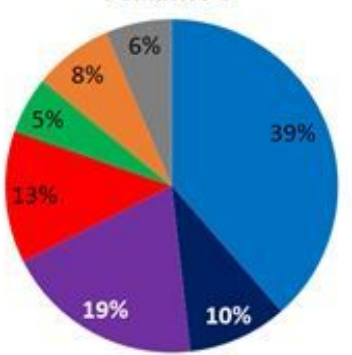

FCMacHT 11

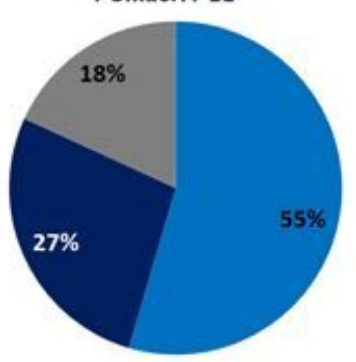

Habitat Use Guilds

$\square$ Intolerant highly rheophilic species

Rheophilic benthic species preferring sandy-gravel bottom substrate

$\square$ Rheophilic water column species preferring sandy-gravel bottom substrate

$\square$ Limnophilic benthic species of moderate tolerance

$\square$ Limnophilic water column species of moderate tolerance

$\square$ Intolerant rheophilic benthic species preferring detritus or pelal bottom substrate
FCMacHT 3

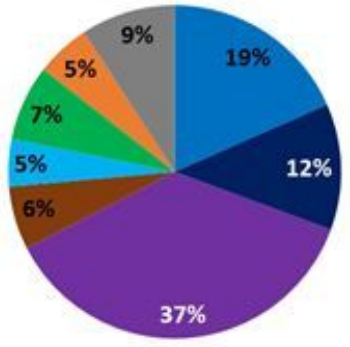

FCMacHT 8

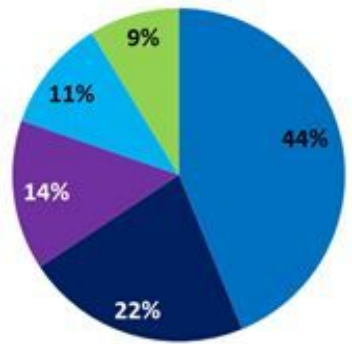

FCMacHT 13

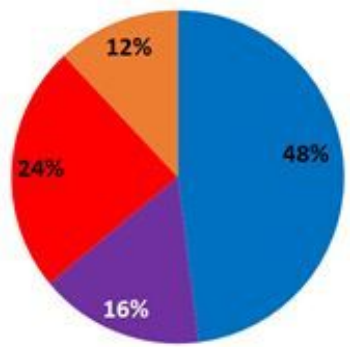

FCMacHT 4

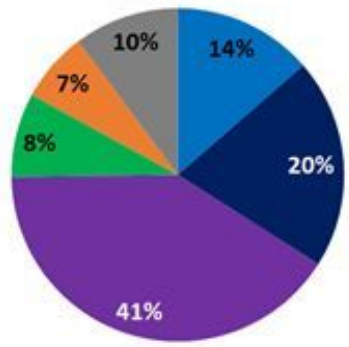

FCMacHT 9

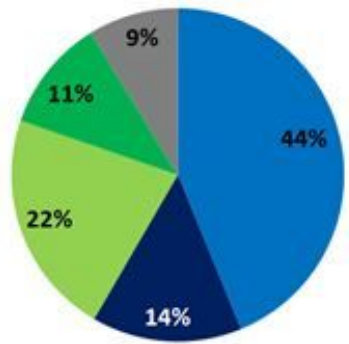

FCMacHT 14

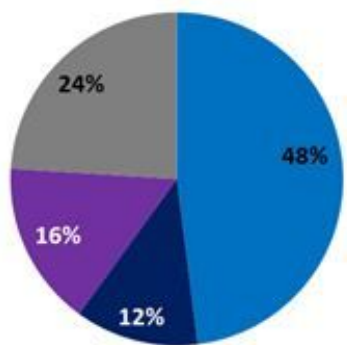

FCMacHT 5

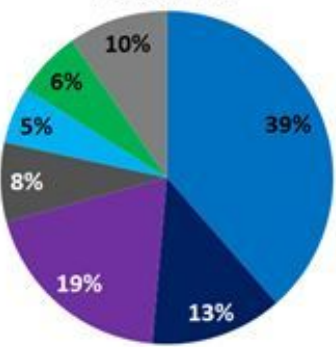

FCMacHT 10

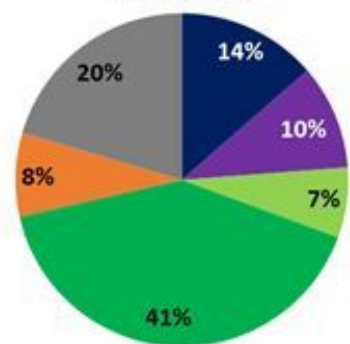

FCMacHT 15

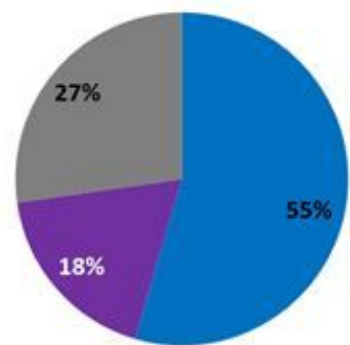

\section{Figure 2}

Structure of expected fish communities presented as a proportion of 11 Habitat Use Guilds for each FCMacHT. Guilds are ordered from more rheophilic / less tolerant to generalist / more tolerant species ${ }^{57}$. For FCMacHT descriptors, refer to Figure 1 and Supplementary Information. 


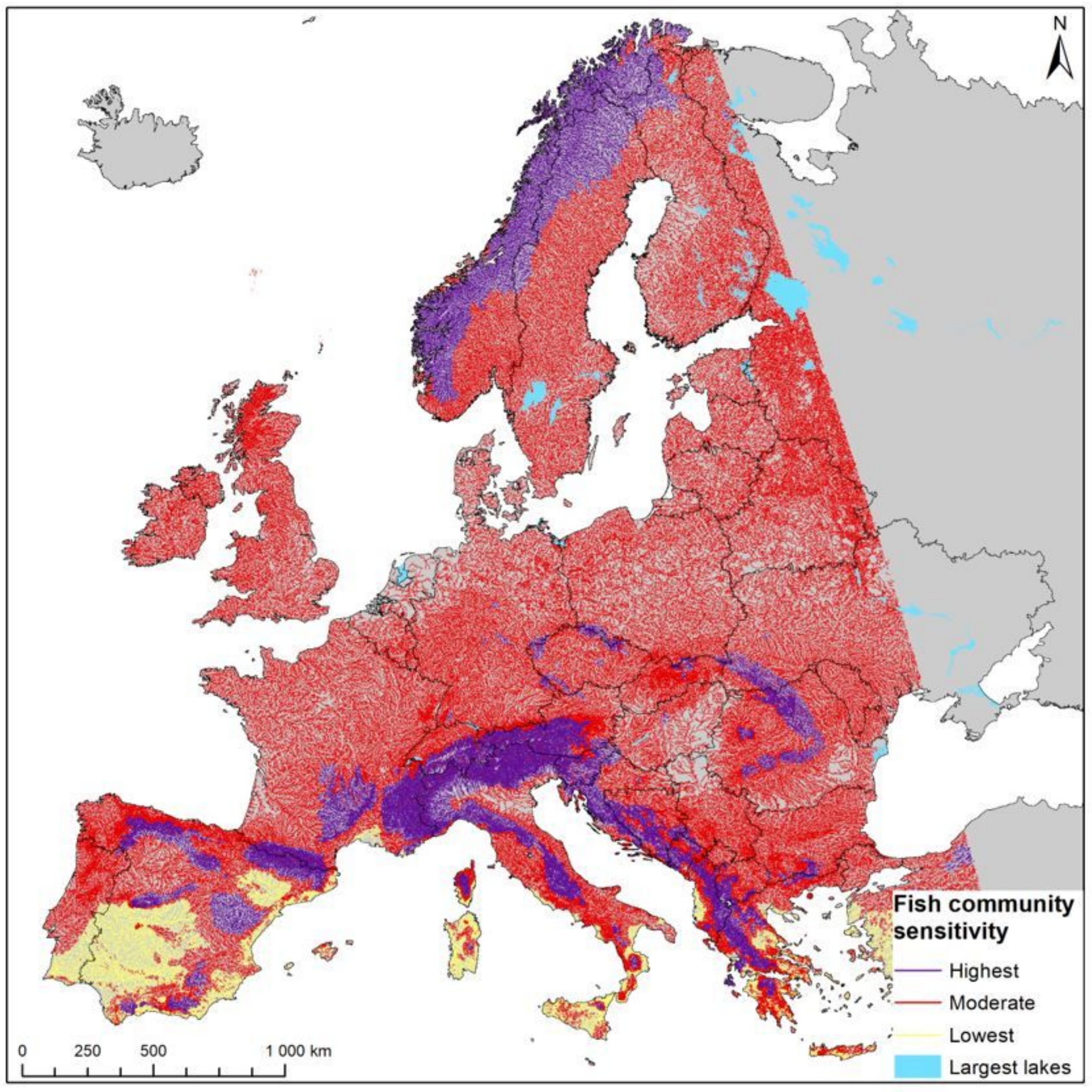

Figure 3

Fish community sensitivity to impounding. 


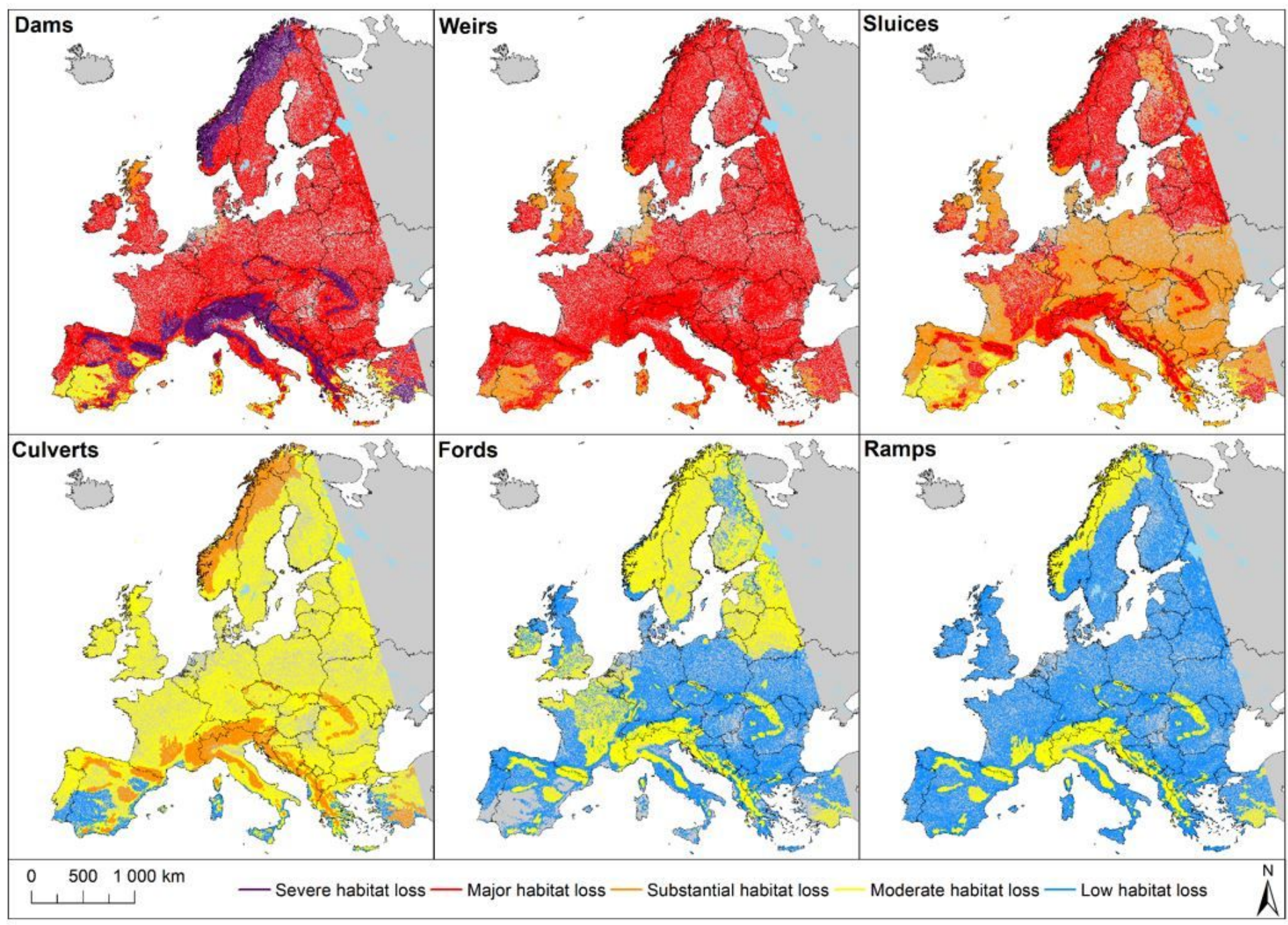

Figure 4

Estimated barrier impact across European rivers with respect to river and barrier type. Results here can help inform where building of new structures is likely to cause large habitat loss or where restoration measures are likely to produce the largest habitat gains. 


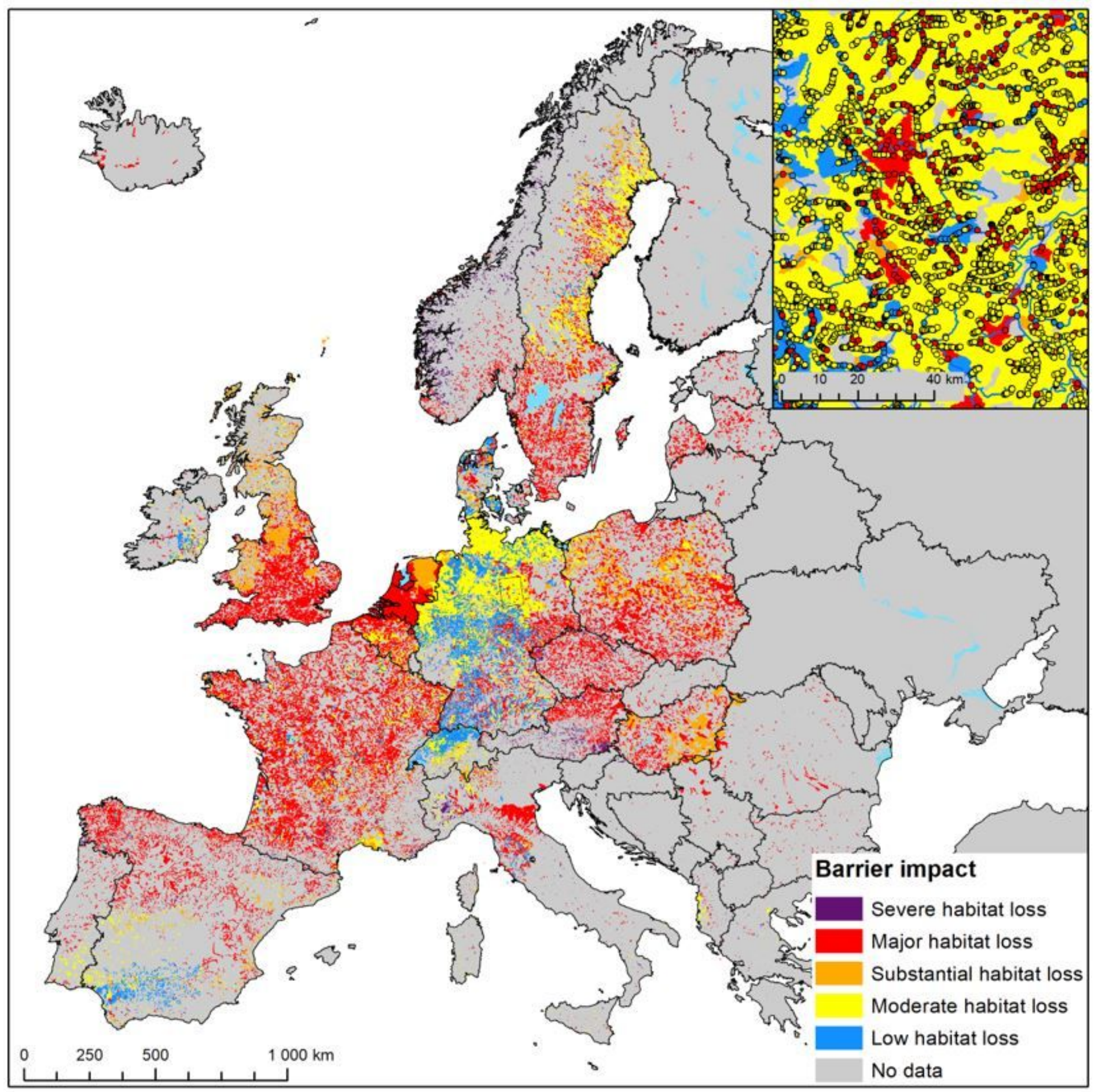

Figure 5

Projected barrier-level impounding impacts in European catchments based on median weighted residual habitat proportion (wRHp) of barriers in the same catchment (refer to Table 1). Points in the inset figure represent individual recorded barriers. Regions with low per barrier impact in Central Europe indicate a relatively high number of small barriers (culverts, fords, and ramps) with low individual impact contained in national registers, while major per barrier impact in other parts of Europe indicates the prevalence of a relatively high number of large barriers and sensitive fish communities. Data sources: AMBER Barrier Atlas (acc. Nov. 2020) ${ }^{30}$ for barrier locations, CCM v2.1 ${ }^{46}$ for river segments and catchments. 


\section{Supplementary Files}

This is a list of supplementary files associated with this preprint. Click to download.

- 20211129HSBIPSwRHPcalculationmatrix.xIsx

- 2022121Barrierimpactv10ALLExtendedData.docx

- Tables12.docx 